\title{
A PESQUISA FORMAÇÃO NA EDUCAÇÃO INFANTIL: FUNDAMENTOS E PRINCÍPIOS $^{1}$
}

\author{
FORMACIÓN DE INVESTIGACIÓN EN EDUCACIÓN INFANTIL: FUNDAMENTOS \\ Y PRINCIPIO
}

\author{
THE RESEARCH TRAINING IN EARLY CHILDHOOD EDUCATION: \\ FOUNDATIONS AND PRINCIPLES
}

\author{
Maria de Nazareth Fernandes MARTINS ${ }^{2}$ \\ Maria Vilani Cosme de CARVALHO ${ }^{3}$
}

RESUMO: As ideias apresentadas neste artigo estão relacionadas aos fundamentos e princípios da pesquisa formação como modalidade de pesquisa. A questão que orienta a discussão empreendida é: quais os caminhos e possibilidades de realização da pesquisa formação com professoras da Educação Infantil ao se ter como fundamento a formação humana? Para produzir informações que criassem condições de explicitar os processos constitutivos da prática pedagógica da Educação Infantil mediada pelo brincar, objeto de estudo de tese de doutorado, foi desenvolvido um percurso metodológico com fundamento no Materialismo Histórico-Dialético e na Psicologia Histórico-Cultural. Com base nesses fundamentos, definimos como princípios: Reflexão crítica sobre a prática com seus fundamentos teóricos; Análise de necessidades formativas como mediação para reflexão crítica e condição para o desenvolvimento profissional; Criação de situações de contradição para produção de afetos alegres sobre a formação e sobre o desenvolvimento da prática; Produção do novo sobre o desenvolvimento da prática.

PALAVRAS-CHAVE: Pesquisa formação. Formação humana. Educação infantil.

RESUMEN: Las ideas presentadas en este articulo están relacionadas con los fundamentos $y$ principios de la capacitación en investigación como modalidad de investigación. La pregunta que guía la discusión emprendida es: ¿cuáles son las formas y posibilidades de llevar a cabo una capacitación en investigación con maestros de educación infantil basada en la formación humana? Para producir información que permita aclarar los procesos constitutivos de la práctica pedagógica de la educación de la primera infancia mediada por el juego, objeto de un estudio de tesis doctoral, se desarrolló un curso metodológico basado en el materialismo dialéctico histórico y la psicología histórico-cultural. En base a estos fundamentos, definimos como principios: Reflexión crítica sobre la práctica con sus fundamentos teóricos; Análisis de las necesidades formativas como mediación para la reflexión crítica y la condición para el desarrollo profesional; Creación de situaciones

\footnotetext{
${ }^{1}$ Parecer Consubstanciado do CEP - CAEE 09863219.1.0000.5214.

${ }^{2}$ Universidade Federal do Piauí (UFPI), Teresina - PI - Brasil. Professora Adjunta do Departamento de Métodos e Técnicas de Ensino. Doutorado em Educação (UFPI). ORCID: https://orcid.org/0000-0001-7486-888X. Email: nazarethfernandesmartins@ufpi.edu.br

${ }^{3}$ Universidade Federal do Piauí (UFPI), Teresina - PI - Brasil. Professora Associada do Departamento de Fundamentos da Educação. Doutorado em Educação (PUCSP). ORCID: https://orcid.org/0000-0002-1675-1808. E-mail: vilacosme@ufpi.edu.br
} 
contradictorias para la producción de afectos felices en la formación y el desarrollo de la práctica; Producción de lo nuevo sobre el desarrollo de la práctica.

PALABRAS CLAVE: Formación en investigación. Formación humana. Educación infantil.

ABSTRACT: The ideas presented in this article are related to the foundations and principles of the research training as a research modality. The question that leads the discussion undertaken is: which ways and possibilities of carrying out the research training with Early Childhood Education teachers for having the human training as a base? To produce information that could create conditions to clarify the constitutive processes of the pedagogical practice of Early Childhood Education mediated by the playing practice, study object of doctoral thesis, a methodological path was developed based on Dialectic Historical Materialism and on the Historical and Cultural psychology. Based on these foundations, we have defined as principles: Critical reflection on the practice with its theoretical foundations; Analysis of training needs as mediation for the critical reflection and condition for the professional development; Creation of situations of contradition for the production of joyful affections about the training and about the practice development; Production of what is new on the practice development.

KEYWORDS: Research training. Human training. Early childhood education.

\section{Notas introdutórias}

Iniciamos a discussão sobre a pesquisa formação ressaltando que para produção de conhecimento científico, como explicita Afanasiev (1982), são elaborados ideias, noções, juízos que precisam evoluir para se transformarem em teoria científica:

No processo de realização da ideia e no decurso da pesquisa nascem noções, imagens, juízos que concretizam a ideia, a encarnam em teses científicas, conclusões e leis que, depois de serem verificadas pela prática, formam finalmente no seu conjunto e unidade, uma teoria científica (AFANASIEV, 1982, p. 167).

No decurso da pesquisa é exigido ao pesquisador ou pesquisadora a organização de caminhos que possibilitem chegar ao concreto pensado. Este concreto que constitui a realidade investigada é uma síntese de múltiplas determinações, e para ser desvelada necessita ter como princípio o movimento da vida, a constituição do ser.

A realidade que se manifesta em sua aparência, na pesquisa formação, é investigada, porque buscamos chegar a sua essência, que não é alcançada por pesquisas mecanicistas, pragmáticas, deterministas, mas por pesquisas firmadas na compreensão da realidade constituída por suas leis, com a explicitação de suas conexões internas, na realidade formada por contradições que incidem sobre os sujeitos e geram transformação, na totalidade como 
contradição e na contradição como totalidade (KOSIK, 1976). Seguindo essa lógica, a pesquisa formação que realizamos se constituiu em um processo revelador das múltiplas determinações da prática pedagógica da Educação Infantil mediada pelo brincar.

Para irmos ao encontro das múltiplas determinações da prática pedagógica, a pesquisa formação que foi realizada, tendo como fundamento o Materialismo Histórico-Dialético e a Psicologia Histórico-Cultural, justifica-se, também, pelo fato dela visar conhecer o desenvolvimento do psiquismo humano na relação dialética do indivíduo com a realidade objetiva e subjetiva.

Assim, explicitamos que o processo de realização de pesquisa no Brasil e em outros países tem apresentado mudanças na forma de desenvolvimento. As pesquisas que se fundamentam na lógica dialética são pesquisas que rompem com a consideração de ser de abordagem qualitativa ou quantitativa (FERNANDES, 2017; IBIAPINA, 2010; MARQUES, 2014; SINGULANI, 2016; TEIXEIRA, 2014). Isso ocorre quando é considerada a relação entre os aspectos constituintes da realidade para se produzir conhecimento que vá além da aparência.

A mudança a que nos referimos foi possibilitada pela base teórico-metodológica que fundamenta os trabalhos mencionados anteriormente, porque a lógica seguida é que aspectos quantitativos e qualitativos estão em constante relação, imprimindo mudanças e transformações na realidade. É desta relação, expressa na lei da dialética, da transformação da quantidade em qualidade (LEFEBVRE, 1975) que encontramos fundamento para a pesquisa formação realizada.

Outro fator que tem sido questionado e apresenta mudanças refere-se aos tipos de metodologia de pesquisa. Durante as décadas de 1960 a 1990, o processo de formação de professores passou a considerar a escola e os profissionais da educação apenas como objeto de pesquisa (GATTI; BARRETO, 2009). Numa subdivisão do trabalho, assim como explica Marx (1996), que caracteriza os vários estágios do desenvolvimento da sociedade capitalista, o pesquisador passou a ser um profissional, e o professor pesquisado outro. Isso demarca muitas pesquisas, nas quais o pesquisador produz dados sobre o objeto de estudo e ao pesquisado cabe apenas a tarefa de fornecer esses dados. Essa forma acaba por determinar relações entre eles que se dicotomizam, sendo realizadas atividades diferentes.

Mas ambos são professores e devem ter a pesquisa como princípio constitutivo de seu trabalho. O que implica processos formativos para a professora que realiza a pesquisa formação como produtora de um relatório científico e para a professora que também realiza pesquisa formação, porém com o objetivo de desenvolver a prática pedagógica. A 
convergência reside no desenvolvimento profissional da professora/pesquisadora e das professoras/pesquisadas.

A pesquisa formação como modalidade de pesquisa objetiva criar condições de conhecimento e transformação da prática pedagógica por meio da reflexão crítica. $\mathrm{O}$ movimento seguido foi tratar do que compreendemos por pesquisa e formação, porque realizar esse tipo de pesquisa, e também como a formação da Educação Infantil foi constituída. E, para singularizar e particularizar a pesquisa formação desenvolvida, apresentamos os seus princípios constitutivos para criar condições das partícipes refletirem criticamente sobre a prática pedagógica com vistas ao desenvolvimento profissional. Citamos, também, outras formas de realizar a pesquisa formação com as outras denominações adotadas (ALVORADA PRADA, 2012; FREIRE, 1987, 1977; GATTI; BARRETTO; ANDRÉ; ALMEIDA, 2019; IBIAPINA; BANDEIRA; ARAUJO, 2016; MORIN, 2004). Na próxima seção tratamos da compreensão de pesquisa formação como modalidade de pesquisa que visa o desenvolvimento profissional dos envolvidos no processo.

\section{A pesquisa formação e o processo de formação humana: estudo e reflexão sobre os fundamentos da prática pedagógica da Educação Infantil}

Com base na pesquisa como princípio constitutivo da atividade docente, utilizamos a pesquisa formação como modalidade de pesquisa que realiza atividades de formação e de produção de conhecimento de forma interdependente, em que a formação orienta a produção dos dados, e estes explicitam necessidades formativas que orientam os estudos da formação.

A proposta desenvolvida tem como fundamento a totalidade, expressa na realidade concreta que constitui a professora pesquisadora, que tem um projeto de pesquisa a desenvolver em nível de doutorado, e as professoras partícipes da pesquisa, que têm a formação como mediação para o desenvolvimento da prática pedagógica.

A compreensão de formação e de pesquisa é de atividades que medeiam o desenvolvimento profissional. A questão que devemos esclarecer é a compreensão explícita destas atividades como unidade que compreende a relação objetividade/subjetividade na produção do conhecimento. A unidade de que tratamos na pesquisa formação é determinante para o desenvolvimento profissional ao buscar a produção de novas relações das professoras com o conhecimento sobre o desenvolvimento infantil e sobre o brincar, com a prática pedagógica realizada e com as exigências da Secretaria de Educação do Município de Teresina/PI. 
Assim, a pesquisa formação que apresentamos como recorte do relatório da tese de Martins (2019), teve o objetivo de mediar o desenvolvimento profissional das professoras partícipes, ancorada nas ações de estudo e de escrita sobre o processo formativo, como necessidade para a formação que visa à reflexão crítica sobre a prática pedagógica.

A pesquisa é uma atividade humana para produção da cultura, e quando esta se relaciona ao desenvolvimento do conhecimento científico exige rigor, sistematização e fundamento numa base teórica. Portanto, esta atividade humana, na realização da prática pedagógica, visa desenvolver o pensamento crítico reflexivo. Reflexividade esta definida como processo que culmina no reconstruir de práticas, primeiro em nível de movimento de pensamento e depois em ação no mundo.

Com base nesta compreensão de pesquisa, a formação de que tratamos é a que humaniza. Assim como Vieira Pinto (2010) e Saviani (2012), compreendemos que a formação ocorre por meio da educação e se justifica falar de educação para humanizar quando Saviani (2012) reitera a existência de educação que desumaniza quando deforma o ser humano. A pesquisa formação se justifica na luta por uma educação formadora, humanizadora. E Marx (2010) corrobora ao ressaltar que a formação humana ocorre por meio do processo histórico de objetivação do gênero humano e de sua vida como ser social.

A pesquisa formação é uma modalidade de pesquisa que visa ampliar o processo de humanização por meio da reflexão crítica sobre práticas educativas, sejam elas pedagógicas ou docentes, e as teorias que as fundamentam. E, quanto ao processo de humanização, relacionamos ao que Politzer (1970) enfatiza quando trata da luta contra o capitalismo, ao considerar que, para nos humanizarmos, precisamos combater o que nos desumaniza, isso porque a realidade é dialética. Fazemos isso quando realizamos pesquisa e formação como atividades constitutivas do processo de humanização.

Corroboram com esta perspectiva de relacionar a pesquisa formação com o processo de humanização as ideias de Freire (1987), ao tratar da humanização/desumanização. O autor ressalta que:

Constatar esta preocupação implica, indiscutivelmente, reconhecer a desumanização, não apenas como viabilidade ontológica, mas como realidade histórica. É também, e talvez, sobretudo, a partir desta dolorosa constatação que os homens se perguntam sobre a outra viabilidade - a de sua humanização (FREIRE, 1987, p. 40).

Humanização e desumanização, na perspectiva freireana, estão implicadas pela busca incessante dos seres humanos pelo conhecimento, pela sua incompletude, pela desalienação, 
pela formação de seres para si, conforme explicita Duarte (2013). A contradição entre humanização e desumanização gera o movimento do pensamento, as idas e vindas dos questionamentos que nos fazemos sobre a realidade na qual atuamos como profissionais e em que desejamos imprimir mudanças com vistas à formação para humanização.

Nessa lógica, as professoras de Educação Infantil, na medida em que lutam para superar práticas biologizantes e de mera escolarização (LAZARETTI, 2013), estão buscando combater o desumano na formação das crianças. E, podemos criar possibilidades de a professora refletir criticamente sobre este processo quando utilizamos a pesquisa formação como caminho para estabelecer ligações internas entre a prática desenvolvida e a teoria sobre o desenvolvimento infantil, pela mediação da reflexão crítica que analisa o cotidiano para reconstruí-lo. Isso foi possível nas Oficinas Pedagógicas (Oficinas de Brincar), como, também, nos momentos da Entrevista Reflexiva Coletiva, nos registros escrito na forma do Memorial Reflexivo do Processo Formativo e das Cartas Pedagógicas ${ }^{4}$.

Ao abordarmos a pesquisa formação estamos estabelecendo relação com a formação de professores, e as pesquisas que têm esse foco são identificadas como pesquisas sobre a formação inicial (RIBEIRO, 2015) e pesquisas sobre a formação contínua (LEITE, 2017; MASSARO, 2016). Quando tratam de formação contínua, elas podem estar relacionadas a professores iniciantes (BANDEIRA, 2014) e formação em serviço (BAHIA; MOCIUTTI, 2017; SANTA’NNA, 2016; ZURAWSKI, 2009); como, também, podem estar relacionadas com a definição de desenvolvimento como unidade para tratar da pesquisa formação, possibilidade de desenvolvimento profissional ao criar condições de surgimento do novo. É desta pesquisa formação que tratamos.

Foi nesta perspectiva que as Oficinas de Brincar $^{5}$ foram realizadas e envolveram momentos de reflexão crítica sobre a prática pedagógica mediada pelos fundamentos teóricometodológicos da Psicologia Histórico-Cultural, pelos relatos das atividades desenvolvidas, pelos questionamentos sobre aspectos do desenvolvimento infantil realizados pelas professoras e sobre a atividade de brincar, fonte de desenvolvimento infantil que "se realiza em condições de relação recíproca com o meio, quando a forma ideal, terminal, a que deve

\footnotetext{
${ }^{4}$ No processo de produção das informações sobre o objeto de estudo da tese, prática pedagógica mediada pelo brincar (MARTINS, 2019), foram realizadas entrevistas, oficinas pedagógicas e registro escrito na forma de memorial e de cartas pedagógicas.

${ }^{5}$ As Oficinas de Brincar tiveram como estrutura de ações: jogos, leitura de crônicas, apreciação de obras de arte, atividades com instrumentos musicais, brincadeiras diversas como momento inicial dos encontros de formação, momentos de diálogo sobre o que as professoras desejavam conversar naquele encontro, que pode ser referente à atividade de acolhimento, a questões relativas à escola, às crianças ou às atividades desenvolvidas em sala de aula, e estudo de textos sobre a atividade de brincar e desenvolvimento infantil.
} 
surgir ao final do desenvolvimento" (VIGOTSKI, 2018, p. 85), já existe e medeia a aprendizagem.

$\mathrm{Na}$ Educação Infantil, por conta das condições históricas de seu surgimento, essa discussão de formação para o desenvolvimento profissional esteve atrelada à formação inicial, porque a realidade apresentava um número significativo de professores atuando sem formação específica (GATTI; BARRETO, 2009), como determina a Lei de Diretrizes e Bases da Educação no 9.394/96 no seu artigo 61 (BRANDÃO, 2010).

No Piauí esta realidade não foi diferente, de acordo com pesquisa de Lima (2016), que envolveu 8.156 professores atuantes na Educação Infantil no ano de 2013. O perfil é formado por professores com formação em nível médio, Normal Superior, Ensino Fundamental completo e incompleto, sendo a formação contínua quase inexistente.

Esses dados são relevantes para validar a necessidade de desenvolvimento de pesquisa formação na Educação Infantil como forma de criar condições da formação contínua se efetivar e gerar contextos de reflexão crítica sobre as práticas que nela se realizam. Baseado na pesquisa de Lima (2016), podemos mencionar as políticas de formação do Ministério da Educação para a Educação Infantil, como o ProInfantil, um curso em nível médio a distância, na Modalidade Normal, destinado aos profissionais que atuavam nas creches e pré-escolas sem formação específica. O ProInfantil foi desenvolvido em parceria com os municípios que recebiam o material do Ministério da Educação (MEC) e deveriam ofertar a infraestrutura e recursos humanos para acompanhar o desenvolvimento das ações de formação.

O ProInfantil foi lançado em 2005, e de acordo com a pesquisa de Lima (2016), no ano de 2013 ainda existiam professores sem formação em nível médio atuando na Educação Infantil. O que significa que transcorridos 08 anos, o Programa não tinha atingido seu objetivo no Piauí, de formar, ao menos em nível médio, profissionais atuantes nas salas de aula de creches e pré-escolas da Educação Infantil.

Com base nestes dados, podemos inferir que a formação contínua para profissionais da Educação Infantil é recente e a própria formação inicial foi contemplada no Projeto Pedagógico do Curso de Pedagogia (PPC) da Universidade Federal do Piauí (UFPI) somente no ano de 2009, quando passou a habilitar para atuação nesta etapa de ensino.

A pesquisa formação é uma forma de realizar a formação contínua que busca problematizar a prática e a formação realizada pelos professores, para tomada de consciência sobre os conhecimentos produzidos no percurso formativo e as ações realizadas para mediar a formação de crianças. Para Gatti et al. (2019, p. 17): “Ao problematizar as questões ligadas à 
formação de professores e ao trabalho docente, objetiva-se a criação de condições para mudanças, uma vez que não se está problematizando por deleite abstrato".

É desta perspectiva que Gatti et al. (2019) compreendem a formação de professores como necessidade para uma educação que atenda as exigências da sociedade. Isso porque, não é possível pensar a educação escolar sem profissionais formados, sem um nível de consciência elevado sobre os aspectos históricos e sociais da sociedade, sobre as demandas globais, nacionais e locais. Os profissionais da educação não são indivíduos com vocação, que trabalham simplesmente por amor, mas devem ter formação sólida e de forma permanente. Desta forma, Gatti et al. (2019, p. 19) explicitam:

\begin{abstract}
A docência deixou de ser uma ação espontânea, que pode ser desenvolvida por intuições, apenas, para se tornar campo de ação com base em fundamentos filosófico-sociais, histórico-psicológicos e fundamentos de práticas específicas que demandam domínio de conhecimentos integrados a conhecimentos científicos e humanistas para a ação educacional voltada às novas gerações, em que linguagens, tecnologias e estruturas interpretativas constituem seu cerne.
\end{abstract}

Com base nestes argumentos, evidenciamos que as políticas de formação atendem aos interesses da sociedade capitalista com alto índice de desigualdade social, e estão pautadas na fragilidade da formação dos professores da Educação Infantil. Necessitamos superar a falsa consciência dessas políticas que, de forma intencional, não garantem um mínimo de formação aos profissionais da educação, e isso reverbera na qualidade das práticas desenvolvidas, visando somente ao processo de aquisição das habilidades específicas e com predomínio da dimensão cognitiva sobre as demais dimensões que constituem o desenvolvimento infantil.

A realidade da formação de professores da Educação Infantil justifica a necessidade de realização da pesquisa formação que desenvolvemos, pois, tendo como fundamento o processo de reflexão crítica sobre a prática, conforme Freire (1977) e Liberali (2010), a mesma atende às necessidades de formação dos professores e cria as condições desta reflexão.

Zurawski (2009), no desenvolvimento de sua dissertação sobre formação de professores da Educação Infantil, fez uso da pesquisa formação e elaborou uma etapa deste processo, chamada de cadeia formativa. Essa cadeia teve a função de demarcar conteúdos fundamentais do processo formativo no movimento de levantamento das necessidades, na observação da prática docente, nos encontros de formação e rodas de conversa. Esses conteúdos são denominados pela autora de temas.

A proposta de Zurawski (2009) se aproxima da que propomos por objetivar mudança nas práticas docentes - embora na sua pesquisa o objeto seja o trabalho com as famílias na 
educação da criança de creche - e, também, por considerar a necessidade de conhecer o que as crianças, professores e formadores necessitam aprender. Mas a base teórica que fundamenta a pesquisa formação realizada em nível de doutorado diverge da proposta da autora mencionada, porque consideramos como fundamental analisar as necessidades formativas no processo e não apenas no início, como é mencionado por Zurawski (2009), que ao tratar da cadeia formativa, afirma que esta orienta a elaboração do plano de formação.

Do que foi discutido, compreendemos que a pesquisa formação se constitui num movimento de idas e vindas, mediadas pela análise das necessidades formativas para se definirem os conteúdos da formação. No processo, a professora vai aprendendo coisas, gerando dúvidas, produzindo novas necessidades, implicações do processo de reflexão crítica sobre a prática pedagógica da Educação Infantil e sobre a prática da pesquisadora na produção do conhecimento que originou o relatório da tese de Martins (2019). Ambas, pesquisadora e professoras, se formam em dimensões diferentes, mas atendendo às mesmas necessidades formativas inerentes ao processo de realização da prática.

É por esse motivo que corroboramos com a discussão de Gatti et al. (2019) ao tratar da valorização de uma postura investigativa na formação de professores, ao ressaltar a necessidade da relação entre aspectos da formação e do trabalho docente, o que valida a relevância da pesquisa formação como proposta para pensar e realizar a formação de professores.

Existem determinados aspectos do exercício docente que podem ser melhor desenvolvidos a partir da problematização e da investigação sistemática com base em fundamentos e instrumentos teórico-metodológicos. A formação para a investigação auxilia o docente a aprender como olhar para o mundo a partir de múltiplas perspectivas, inclusive as dos alunos [crianças], cujas vivências são muito diferentes das do professor e, sobretudo, a utilizar esse conhecimento para lançar mão de práticas mais equitativas na sala de aula [sala de atividades] (GATTI et al., 2019, p. 188, grifos dos autores).

Nesta relação de pesquisa com formação, Lefebvre (1975) nos auxilia quando explica sobre o processo de produção do conhecimento por meio do movimento do pensamento na luta pela explicação da realidade. Para o autor, o ser humano na busca pelo conhecimento faz um esforço para abstrair, refletir e ampliar sua consciência. E para refletir criticamente, é necessário que o pensamento consiga ligar termos, como o ser e o nada; o devir e o ser; a qualidade e a quantidade; precisa ser movimento de pensamento e pensamento em movimento; precisa evidenciar as contradições e depois as relacionar, definir a unidade entre elas e, por fim, introduzir o novo, o salto, o pensamento que avança. 
O pensamento se destrói enquanto pensamento a partir do momento em que se separa do conteúdo, a partir do momento em que o conteúdo não é posto como conteúdo (natural e social) do pensamento, ainda não apreendido ou apenas globalmente apreendido, ainda não analisado (LEFEBVRE, 1975, p. 179).

O conteúdo do pensamento para o qual desejamos criar condições de ser movimento é o desenvolvimento infantil por meio do brincar, atividade guia e fonte do desenvolvimento da criança, para uma reflexão crítica sobre a prática pedagógica da Educação Infantil. E estamos considerando que a realização da pesquisa formação com vistas à reflexão crítica sobre os fundamentos da prática é possível se for firmada no movimento do conteúdo e na forma de ser professora da Educação Infantil.

Assim, a pesquisa formação é marcada pela reflexão crítica sobre os fundamentos da prática; pela negociação de ações formativas; pela análise das necessidades formativas e por um pensar, sentir e agir que negue o determinismo, um pensar, sentir e agir determinados social e historicamente e com vistas à humanização. Vejamos os princípios constitutivos da pesquisa formação desenvolvida no processo de doutoramento em educação realizado no Programa de Pós-Graduação em Educação - PPGEd/UFPI.

\section{Pesquisa formação e seus princípios constitutivos}

O propósito de definir como pesquisa formação, a modalidade de pesquisa realizada, se ancorou também nas muitas denominações dadas às pesquisas que consideram a unidade pesquisa e formação e nas muitas formas de realizar essa modalidade de pesquisa. E, considerando a historicidade desta modalidade de pesquisa é que apresentamos a seguir algumas formas de realizar a pesquisa com formação de professores, pesquisas que visam estabelecer relações entre pesquisador e pesquisado.

Dentre estas, destacamos a historicidade apresentada por Alvorada Prada (2012) na intenção de demarcar as pesquisas firmadas também na formação. $\mathrm{O}$ autor buscou mapear as denominações dadas pelos autores das dissertações e teses dos Programas de Pós-graduação em Educação das Universidades Brasileiras, no período 1999-2008, às modalidades de pesquisa e/ou metodologias realizadas mediante pesquisas de intervenção para formação de professores. Com esta pesquisa, o autor identificou várias denominações para essa forma de fazer pesquisa com formação. Podemos mencionar a pesquisa-ação, a pesquisa colaborativa e a denominada pelo autor como pesquisa coletiva. 
As pesquisas que Ibiapina, Bandeira e Araujo (2016) desenvolvem são caracterizadas de colaborativas, demarcadas como as que produzem conhecimento mediado por processos investigativos da ação dos professores e com estes professores. Pesquisas realizadas em colaboração entre os participantes da investigação. Existem também as denominadas de pesquisa-ação, e ainda, as pesquisas críticas de colaboração. Outra forma de realizar pesquisa formação é definida por Morin (2004) de pesquisa-ação integral e sistêmica, que considera sua essência ser a participação, e ao exigi-la, os atores são envolvidos em todas as etapas do processo, desde a elaboração do projeto formativo. Assim, todos se transformam em pesquisadores.

Estas formas de fazer pesquisa formação visam ao desenvolvimento profissional dos partícipes envolvidos, caracterizado pela produção de conhecimento e autorreflexão. Mas criar condições de desenvolvimento profissional nos partícipes deste processo que revelem tendências referentes à prática pedagógica e suas relações com a atividade de brincar fazem a pesquisa formação desenvolvida ser particularizada pela produção de diferentes formas de registro para mediar o processo de reflexão crítica, pela análise das significações produzidas no processo de pesquisa como caminho para o desenvolvimento profissional. Isto porque, toda atividade é significada e toda transformação da prática exige transformação das significações, nas e pelas criações de situações de contradição para produção de afetos alegres.

A proposta que se discute e se encaminha é de considerar pesquisa formação para definir instrumentos e formas de utilização destes que não descaracterizem a compreensão da modalidade de pesquisa e a relação desta com a base teórica. São inúmeras as possibilidades que esta metodologia cria. A opção por essa modalidade de pesquisa se explica pela base teórica da tese que se fundamenta nas categorias de mediação e de totalidade como categorias que auxiliam o indivíduo/pesquisadora na explicação da realidade de forma múltipla e em movimento.

É esta compreensão da realidade das professoras que fizeram parte da pesquisa, em relação às necessidades produzidas na realização dos estudos, como também no processo de reflexão crítica e na produção dos instrumentos de registro escrito, na qual fizemos uso do Memorial Reflexivo do Processo Formativo e das Cartas Pedagógicas, além da participação nas Oficinas de Brincar, para, assim, criar condições de gerar desenvolvimento profissional.

No processo de pesquisa formação, os agentes estão implicados por meio de relações, ligações e concatenações fundadas no devir, no processo de conhecer e saber que o 
conhecimento se manifesta de forma aparente, mas a essência pode ser desvelada. A pesquisa formação que foi desenvolvida teve como princípios:

- Reflexão crítica sobre a prática com seus fundamentos teóricos, considerando a prática como critério de verdade que transforma a realidade e condição do desenvolvimento da consciência;

- Análise de necessidades formativas como mediação para reflexão crítica e condição para o desenvolvimento profissional, compreendido como a produção do novo, do desenvolvimento humano;

- Criação de situações de contradição para produção de afetos alegres sobre a formação e sobre o desenvolvimento da prática, por meio da relação do ser humano com o objeto a conhecer;

- Produção do novo sobre o desenvolvimento da prática, sendo realizado de forma compartilhada e como totalidade que se expressa nas múltiplas determinações do ser.

A reflexão crítica sobre a prática permeou todo o processo de realização da pesquisa formação, e foi evidenciada no percurso por meio da apropriação dos fundamentos teóricos sobre o desenvolvimento da criança e sobre a atividade de brincar, que produziram novas necessidades formativas referentes ao desenvolvimento da prática pedagógica.

As necessidades formativas estão implicadas neste processo de reflexão crítica ao possibilitar às professoras expressarem desejo de aprender sobre o desenvolvimento da criança, sobre como organizar a prática pedagógica guiada pelo objetivo de desenvolver a criança integralmente, e não apenas em algumas habilidades que priorizem somente a dimensão cognitiva.

No percurso da pesquisa formação, a criação de situações de contradição foi gerada desde o momento em que se problematizou as narrativas da entrevista reflexiva coletiva e destacamos trechos nos quais as professoras partícipes abordavam a presença do brincar nas atividades desenvolvidas e as relacionamos às explicações de Vigotski (2018) e seus apropriadores sobre o que é desenvolvimento, e o que é o brincar como atividade principal da criança.

Assim, reiteramos que a criação das condições de desenvolvimento profissional está atrelada à formação que tenha como princípio a reflexão crítica sobre o processo formativo e sobre o desenvolvimento da prática, considerando as condições sociais e históricas, fundamentada nas teorias que medeiam a análise da prática com vistas à produção do novo, 
porque o desenvolvimento profissional ocorre quando são materializadas transformações na prática pedagógica.

O processo de transformação da prática é complexo, é multideterminado. Nesta perspectiva, recorremos a Saviani (2011, p. 91), quando aborda a possibilidade de transformação da prática por meio da reflexão crítica e a precarização das condições para que esta transformação aconteça:

[...] como as condições de desenvolvimento da prática são precárias, também se criam óbices, criam-se desafios ao desenvolvimento da teoria, e isto num duplo sentido: num primeiro sentido, na medida em que, se a prática que fundamenta a teoria e que opera como seu critério de verdade e sua finalidade tem um desenvolvimento precário, enfrentando no âmbito de sua materialidade entraves complexos, ela coloca limites à teoria, dificultando o seu avanço; num segundo sentido, na medida em que as condições precárias da prática provocam a teoria a encontrar as formas de compreender esses entraves e, ao compreendê-los, buscar os mecanismos efetivos e, portanto, também práticos, formulando-os com a clareza que a teoria exige, tendo em vista a sua mobilização para a transformação efetiva dessas mesmas condições.

As condições objetivas e subjetivas de transformação da prática são precárias, como afirma o autor, pelas próprias características da sociedade capitalista, baseada na divisão de classes. Nesta perspectiva, as instituições sociais como a escola findam garantindo esta precarização no ensino. Portanto, a formação deve criar condições de as professoras encontrarem maneiras de resolver esses entraves, e buscarem desenvolver uma prática com vistas à emancipação. É neste terreno que a reflexão crítica se torna necessária ao processo formativo.

Contudo, como atesta Saviani (2011), as condições precárias da prática provocam a teoria a encontrar formas, caminhos, alternativas para compreender esses entraves. $\mathrm{O}$ entrave a que nos referimos é da prática pedagógica que visa apenas alfabetizar as crianças, prática pedagógica com fragilidades no conhecimento sobre a criança e sobre seu processo de desenvolvimento e de aprendizagem.

A explicação de Saviani (2011) nos possibilita mencionar qual é a natureza da reflexão crítica na formação de professores. Ela reside em elevar o nível de consciência sobre a prática desenvolvida, criar motivos para continuar refletindo sobre suas ações na escola para formar indivíduos, neste caso, crianças.

Corroboram com estes argumentos Freire (1977), Zeichner (2008), Ibiapina (2010), Carvalho (2012), ao considerarem que o processo de reflexão crítica possibilita aos profissionais tomarem decisões acerca de suas atividades de forma consciente, pois 
conseguem analisar as estruturas institucionais e a consciência de quem são, do que fazem e pensam, conseguem olhar a realidade e compreender as contradições que a constituem. Carvalho (2012, p. 101) esclarece que: “os processos formativos mediados pela reflexão crítica podem formar e transformar o professor, constituindo-o como ser para-si; profissional capaz de pensar, de sentir, de agir em direção à transformação social, educacional e escolar”.

A produção do novo sobre a prática foi se constituindo na compreensão mais aprofundada sobre as limitações da prática pedagógica que visava apenas a aprendizagem da leitura e da escrita e de forma repetitiva, por meio de muitas cobranças, porque os conhecimentos dessas habilidades são mensurados em testes e as professoras e escolas são premiadas pelo desempenho das crianças nesses testes.

O que tornou a nossa proposta de pesquisa formação uma situação de contradição, pois o instituído atende as necessidades da sociedade capitalista que almeja sempre um produto final que possa ser agregado à valorização do trabalho docente. A situação de contradição foi criada também quando se atestou a utilização do brincar como estratégia de ensino, e passou também a se pensar no brincar como atividade da criança com suas especificidades e possibilidades de apropriação e objetivação da cultura humana.

$\mathrm{Na}$ pesquisa desenvolvida por Marques (2014, p. 23), a autora se fundamenta em Spinoza (2016) para enfatizar que "a vivência do processo educativo, mediada pela produção de afetos alegres, ajuda professores e alunos a descobrirem o que potencialmente os torna mais felizes". Essa ideia da autora ganha força em nossa pesquisa, porque nela a vivência de afetos alegres criou condições das professoras aumentarem a potência de agir, no que se refere ao desenvolvimento da prática pedagógica. O que as professoras viveram na pesquisa formação gerou a produção de afetos alegres, pois novos sentidos foram produzidos sobre a prática pedagógica que realizavam, sinalizando zonas de sentidos que indicavam possibilidade de mudança.

De certo, a formação desenvolvida por meio da pesquisa formação deve ser espaço e tempo de produção de afetos alegres para aumentar, conforme Spinoza (2016), a potência de agir, seja transformando o pensamento sobre a prática pedagógica, seja transformando essa prática, seja criando motivos para continuar estudando e refletindo sobre o desenvolvimento integral do indivíduo, por meio da produção de novas zonas de sentido. Estas zonas de sentido intencionamos evidenciar nas considerações finais desse artigo. 


\section{Notas inconclusivas}

No processo de produção de conhecimentos sobre os elementos constitutivos da prática pedagógica mediada pelo brincar, as significações produzidas pelas professoras partícipes da pesquisa formação geraram afetos alegres sobre o processo formativo, sobre as possibilidades de compartilhar os desafios da docência da Educação Infantil. Os afetos alegres fizeram das Oficinas de Brincar momentos de risos, de escuta atenta, de beleza estética, de necessidade para as professoras que relataram em suas Cartas Pedagógicas o desejo de continuar estudando sobre o desenvolvimento da criança, de continuar os encontros, independente da finalização da pesquisa que deu origem ao relatório de tese de doutorado.

Os sentimentos produzidos pelas professoras sobre a pesquisa formação oscilavam entre alegria e tristeza, prazer e sofrimento. Era alegria por serem encontros que possibilitavam a escuta atenta, o compartilhar dos desafios da docência. Contudo, também tristeza e sofrimento ao compreenderem a prática como limitante, ao constatarem que não estavam criando condições do brincar acontecer na escola objetivando o desenvolvimento integral da criança. E alegria novamente, ao olharem para a sua prática pedagógica mediada pelo brincar e compreenderem que produziram conhecimento sobre essa prática.

O misto de sentimentos produzidos sobre a pesquisa formação, aliado às explicações sobre a compreensão da prática e a necessidade de fazer diferente, é indicativo da luta interna, da luta de contrários (KOPNIN, 1978; LEFEBVRE, 1975), como condição para surgimento do novo. Os conhecimentos da prática pedagógica alfabetizadora estavam entrando em choque com os conhecimentos sobre o desenvolvimento infantil, com os conhecimentos sobre o brincar como atividade guia do desenvolvimento integral da criança.

Os conflitos se intensificavam quando as professoras, pautadas nos conhecimentos produzidos na pesquisa formação, pensavam em como organizar a prática e não sabiam como fazer isso; então, se cria a necessidade de conhecer mais sobre o brincar e sobre o desenvolvimento da criança.

Com as aprendizagens produzidas, as professoras olharam para prática como algo que pode ser mudado, fundada em conhecimentos sobre o brincar e o sobre o desenvolvimento infantil. As professoras constataram que não é simples relação de apropriação da teoria com a realização da prática pedagógica, mas processo de idas e vindas, permeado de reflexão crítica sobre a docência e sobre a criança e suas necessidades, uma luta entre as novas aprendizagens e as práticas já consolidadas que geraram o desenvolvimento profissional. 


\section{REFERÊNCIAS}

AFANASIEV, V. G. Fundamentos de filosofia. Moscovo: Progresso, 1982.

ALVORADA PRADA, E. Metodologias de pesquisa-formação de professores nas dissertações, teses: 1999-2008. In: SEMINÁRIO DE PESQUISA EM EDUCAÇÃO DA REGIÃO SUL, 9., 2012, Caxias do Sul. Anais [...]. Caxias do Sul, RS: ANPED SUL, 2012.

BAHIA, C. C.; MOCIUTTI, S. A construção da relação creche-família no berçário: contribuição da pesquisa-formação. RIAEE - Revista Ibero-Americana em Educação, Araraquara, v. 12, n. 1, p. 371-386, 2017. Disponível em:

https://periodicos.fclar.unesp.br/iberoamericana/article/view/8646/6271. Acesso em: 12 abr. 2019.

BANDEIRA, H. M. M. Necessidades formativas de professores iniciantes na produção da práxis: realidade e possibilidades. 2014. 248 f. Tese (Doutorado em Educação) - Centro de Ciências da Educação, Universidade Federal do Piauí, Teresina, 2014.

BRANDÃO, C. F. LDB passo a passo: Lei de diretrizes e Bases da Educação Nacional, lei n ${ }^{\circ}$ 9.9394/96, comentada e interpretada artigo por artigo. 4. ed. São Paulo: Avercamp, 2010.

CARVALHO, M. V. C. Formação crítica de educadores e desenvolvimento do professor como ser para si. In: IBIAPINA, M. L. M.; LIMA, M. G. S. B.; CARVALHO, M. V. C. (org.). Pesquisa em educação: múltiplos referenciais e suas práticas. Teresina, PI: EDUFPI, 2012. v. 1.

DUARTE, N. A individualidade para si: contribuição a uma teoria histórico-crítica da formação do indivíduo. 3. ed. Campinas, SP: Autores Associados, 2013.

FERNANDES, A. G. N. A prática pedagógica na educação infantil mediada pelos conceitos da disciplina Psicologia da Educação: realidade e possibilidade na dialética apropriação e objetivação. 2017. 201 f. Tese (Doutorado em Educação) - Centro de Ciências da Educação, Universidade Federal do Piauí, Teresina, 2017.

FREIRE, P. Extensão ou comunicação? Trad. Rosisca Darcy de Oliveira. Rio de Janeiro: Paz e Terra, 1977.

FREIRE, P. Pedagogia do oprimido. 17. ed. Rio de Janeiro: Paz e Terra, 1987.

GATTI, B. A. et al. Professores do Brasil: novos cenários de formação. Brasília: UNESCO, 2019.

GATTI, B. A.; BARRETO, E. S. S. Professores do Brasil: impasses e desafios. Brasília: UNESCO, 2009.

IBIAPINA, I. M. L. M. Reflexão crítica sobre a atividade docente de professores universitários em contexto colaborativo. In: ENCONTRO NACIONAL DE DIDÁTICA E PRÁTICAS DE ENSINO, 15., 2010, Belo Horizonte. Anais [...]. Belo Horizonte: UFMG, 2010. p. 1-12. 1 CD ROM. 
IBIAPINA, I. M. L. M; BANDEIRA, H. M. M.; ARAUJO, F. A. M. (org.). Pesquisa colaborativa: multirreferenciais e práticas convergentes. Teresina: EDUFPI, 2016.

KOPNIN, P. V. A dialética como lógica e teoria do conhecimento. Trad. Paulo Bezerra. Rio de Janeiro: Editora Civilização brasileira, 1978.

KOSIK, K. Dialética do concreto. Trad. Célia Neves e Alderico Toríbio. 2. ed. Rio de Janeiro: Paz e Terra, 1976.

LAZARETTI, L. M. A organização didática do ensino na Educação Infantil: implicações da Teoria Histórico-Cultural. 2013. 204 f. Tese (Doutorado) - Faculdade de Educação, Universidade Federal de São Carlos, São Carlos, 2013.

LEFEBVRE, H. Lógica formal e lógica dialética. Trad. Carlos Nelson Coutinho. Rio de Janeiro: Editora Civilização Brasileira S. A, 1975.

LEITE, S. R. M. Educação e ética: desafios na atuação do professor da infância. 2017. 184 f. Tese (Doutorado) - Universidade Estadual Paulista, Araraquara, 2017.

LIBERALI, F. C. Formação crítica de educadores: questões fundamentais. São Paulo: Pontes, 2010.

LIMA, M. C. B. Quem são os professores da primeira infância? Um estudo sobre o perfil formativo dos professores que atuam na Educação Infantil no estado do Piauí no contexto pós LDB 9.394/96. 2016. 357 f. Tese (Doutorado em Educação) - Centro de Ciências da Educação, Universidade Federal do Piauí, Teresina, 2016.

MARQUES, E. S. A. O socioafetivo mediando a constituição de práticas educativas bem sucedidas na escola. 2014. $324 \mathrm{f}$. Tese (Doutorado em Educação) - Centro de Ciências da Educação, Universidade Federal do Piauí, Teresina, 2014.

MARTINS, M. N. F. Prática pedagógica da educação infantil mediada pelo brincar: de estratégia de ensino à atividade guia do desenvolvimento integral da criança. 2019. $312 \mathrm{f}$. Tese (Doutorado em Educação) - Centro de Ciências da Educação, Universidade Federal do Piauí, Teresina, 2019.

MARX, K. Manuscritos econômico-filosóficos. Trad. Jesus Ranieri. São Paulo: Boitempo, 2010.

MARX, K. O capital: crítica da economia política. Trad. Regis Barbosa e Flávio R. Kothe. São Paulo: Editora Nova Cultural Ltda, 1996. t. 1. v. 1.

MASSARO, M. Formação Continuada do Professor de Educação Infantil no Contexto de Sistemas de Comunicação Suplementar e Alternativa. 2016. 131 f. Tese (Doutorado) Faculdade de Filosofia e Ciências, Universidade Estadual Paulista, São Paulo, 2016.

MORIN, A. Pesquisa-ação integral e sistemática: uma antropopedagogia renovada. Trad. Michel Thiollent. Rio de Janeiro: DP\&A, 2004. 
POLITZER, G. Princípios fundamentais de filosofia. Trad. João Cunha Andrade. São Paulo: Hemus - Livraria Editora Ltda., 1970.

RIBEIRO, L. M. Saberes e metodologia da educação infantil: o curso de Pedagogia. 2015. 250 f. Tese (Doutorado) - Centro de Educação, Universidade Federal de Alagoas, Maceió, 2015.

SANT'ANNA, M. M. M. Formação continuada em serviço para professores da educação infantil sobre o brincar. 2016, 166 f. Tese (Doutorado em Educação) - Faculdade de Filosofia e Ciências, Universidade Estadual Paulista, São Paulo, 2016.

SAVIANI, D. Escola e democracia: teorias da educação, curvatura da vara, onze teses sobre a educação política. 42 ed. Campinas: Autores Associados, 2012.

SAVIANI, D. Pedagogia histórico-crítica: primeiras aproximações. 11 ed. rev. Campinas: Autores Associados, 2011.

SINGULANI, R. A. D. A situação social de desenvolvimento das crianças de dois a três anos: um estudo com enfoque nas experiências vivenciadas na escola de educação infantil. 2016. 177 f. Tese. (Doutorado) - Faculdade de Filosofia e Ciências, Universidade Estadual Paulista, São Paulo, 2016.

SPINOZA, B. Ética. Trad. Tomaz Tadeu. 2. ed. Belo Horizonte: Autêntica Editora, 2016.

TEIXEIRA, C. S. M. Ser "o faz-tudo" na escola: a dimensão subjetiva do trabalho do coordenador pedagógico. 2014. 261 f. Tese (Doutorado em Educação) - Centro de Ciências da Educação, Universidade Federal do Piauí, Teresina, 2014.

VIEIRA PINTO, Á. Sete Lições sobre educação de adultos. 16. ed. São Paulo: Cortez, 2010.

VIGOTSKI, L. S. 7 aulas sobre L. S. Vigotski: sobre os fundamentos da pedologia. Rio de Janeiro: E-papers, 2018.

ZEICHNER, Z. M. Uma análise crítica sobre a "reflexão" como conceito estruturante na formação docente. Revista Educação e Sociedade, Campinas, v. 29, n. 103, p. 535-554, maio/ago. 2008.

ZURAWSKI, M. P. V. Escrever sobre a própria prática: desafios na formação do professor da primeira infância. 2009. 171 f. Dissertação (Mestrado) - Universidade de São Paulo, São Paulo, 2009. 


\section{Como referenciar este artigo}

MARTINS, M. N. F.; CARVALHO, M. V. C. A pesquisa formação na educação infantil: fundamentos e princípios. Revista Ibero-Americana de Estudos em Educação, Araraquara, v. $16, \quad$ n. 3 , p. 2221-2239, jul./set. 2021. e-ISSN: 1982-5587. DOI: https://doi.org/10.21723/riaee.v16i3.15420

Submetido em: $20 / 12 / 2020$

Revisões requeridas em: 18/01/2021

Aprovado em: 21/02/2021

Publicado em: 01/07/2021 